\title{
EL PERMISO DE LACTANCIA EN LA LEGISLACIÓN SOCIAL FRANQUISTA. ANÁLISIS DE NORMAS SECTORIALES Y DE EMPRESA
}

\author{
Dra. Elisabet Velo i Fabregat \\ Profesora asociada de Historia del Derecho y las Instituciones del Departamento de \\ Derecho Público y Ciencias Históricojurídicas \\ Facultad de Derecho, Universidad Autónoma de Barcelona
}

A l'Arnau, pels mesos de lactància compartits.

\begin{abstract}
Actualmente, el permiso de lactancia es un derecho indiscutible que madres y padres pueden disfrutar en aras de la igualdad de género y la conciliación familiar, considerando que es un beneficio para el bebé. La legislación social es un buen indicador para comprobar la salud que gozan en cada momento los derechos de la clase trabajadora y, en el caso que nos ocupa, los derechos entorno a la lactancia, íntimamente relacionado con los derechos de las mujeres en el ámbito laboral, al que podemos añadir el derecho a una maternidad sin riesgos para la salud de la madre. En este artículo se analiza la regulación del permiso de lactancia durante la época franquista y se analizaran normas sectoriales y de empresa para comprobar si este derecho quedaba recogido en las mismas más allá de la legislación social general.

Currently, the lactation permit is an indisputable right that mothers and fathers can enjoy for the sake of gender equality and family conciliation, considering that it is a benefit for the baby. Labor legislation is a good indicator to check the health enjoyed at all times by the rights of the working class and, in the case at hand, the rights around breastfeeding, closely related to the rights of women in the workplace, to which we can add the right to a motherhood without risks for the mother's health. This article analyzes the regulation of the lactation permit during the Franco era and analyzed sectorial and company rules to check whether this right was included in them beyond general labor legislation.
\end{abstract}

IUSLabor 1/2019, ISSN 1699-2938, p. 355-373

DOI. 10.31009/IUSLabor.2019.101.14

Title: The lactation permit in Franco's era labor legislation. Analysis of sectorial and company rules. 
Palabras clave: permiso de lactancia, legislación social, franquismo, mujeres, maternidad, Reglamentaciones Nacional de Trabajo, Ordenanzas Laborales.

Keywords: lactation permit, labor legislation, Franco's dictatorship, women rights, motherhood, National Labor Regulations, Labor Ordinances.

\section{Sumario}

1. Introducción

2. Antecedentes históricos del permiso de lactancia

3. Legislación laboral franquista: de la expulsión de las mujeres del mercado de trabajo a un retorno con reservas.

4. Análisis de Reglamentaciones Nacionales de Trabajo y Ordenanzas Laborales sectoriales y de empresa

5. Conclusiones

6. Bibliografía 


\section{Introducción}

La lactancia materna es uno de los bienes más preciados que todo recién nacido tiene derecho a disfrutar, así como de las madres que desean dar el pecho. La Organización Mundial de la Salud (en adelante, OMS) recomienda la lactancia materna exclusiva en los primeros seis meses de vida: "es la forma ideal de aportar a los niños pequeños los nutrientes que necesitan para un crecimiento y desarrollo saludables". Actualmente, el debate sobre éste tipo de lactancia es una de las cuestiones más relevantes que se plantea entorno a la maternidad y que preocupa a muchas madres, primerizas o no, por la gran presión social que existe entorno a ellas para que den el pecho a sus hijos, y si puede ser que cumplan, como mínimo, el tiempo recomendado por la OMS. No siempre es fácil cumplir las expectativas, ya sean de la madre consigo misma, con su hijo recién nacido o el entorno. Iniciar la lactancia materna después del parto es una ardua tarea y por ello es necesario un buen acompañamiento desde el mismo momento del alumbramiento. El acompañamiento profesional, así como la paciencia y estima del entorno más inmediato, son básicos para tomar la decisión más acorde con la conciencia y posibilidades de la madre, así como para iniciar el duro camino que es dar el pecho si así lo desea, pues muchas madres toman la libre decisión de preferir la lactancia artificial.

La legislación laboral actual ha dado importantes pasos para la igualdad entre mujeres y hombres, siendo el permiso por maternidad y paternidad, así como el de lactancia, de los instrumentos más relevantes. Aun así, cabe señalar que estos permisos son aún insuficientes para una lactancia materna que alcance su exclusividad a los seis meses referidos anteriormente y, aunque actualmente existan instrumentos para sacar la leche de la madre, no siempre es fácil disponer del tiempo (sobre todo mientras se está dentro de la jornada laboral) y el espacio suficientes para una cómoda extracción.

El permiso de maternidad y paternidad son imprescindibles para el descanso y recuperación física y mental de la madre después del parto, así como para el cuidado del bebé en los primeros meses de vida por parte de ambos progenitores. Estos permisos han seguido su evolución legislativa al largo del tiempo. Una legislación que no ha implicado decididamente a los padres hasta hace muy pocos años ${ }^{2}$ y que es aún hoy día

\footnotetext{
${ }^{1}$ Para más información: https://www.who.int/topics/breastfeeding/es/

${ }^{2}$ Un tiempo atrás, los padres disponían de sólo tres días por nacimiento del bebé y no es hasta 2016 que se amplía el permiso de paternidad de dos a cuatro semanas. La previsión de aumentar el permiso de paternidad a 8 semanas hasta llegar a la equiparación de las 16 semanas del permiso de maternidad en 2021 se aprueba el 1 de marzo de 2019 mediante Decreto-ley, después que el presidente del Gobierno, Pedro Sánchez, convocara elecciones generales para el 28 de abril de 2019. El Real Decreto-ley 6/2019,
} 
una de las cuestiones que inciden más en la desigualdad laboral entre mujeres y hombres. La paternidad y maternidad han sido una realidad que ha afectado mucho más a las mujeres que a los hombres en el ámbito laboral. Los datos sobre excedencias por cuidados de menores (y mayores), jornadas laborales reducidas o parciales y permisos de paternidad efectivamente ejercidos por hombres, reflejan que las madres siempre salen perdiendo. Perdiendo oportunidades laborales, salario, formación, empleos más cualificados y posibilidades de ascenso, entre otros, porque son ellas las que cuidan, en un número muy superior, de los pequeños. ${ }^{3}$ En cualquier caso, ésta desigualdad no sólo se corrige aprobando e implementando una legislación laboral que la subsane, sino que es necesario y urgente un cambio de mentalidad radical en éste sentido, ya sea de las familias implicando a los padres (y a los abuelos hombres), ya sea de las empresas aceptando que la maternidad y la paternidad es un deseo que, de hacerse realidad, deben ejercer tanto las madres como los padres en igualdad, sea en parejas heterosexuales o homosexuales. En cualquier caso, sigue siendo una reivindicación que en pleno siglo XXI aún no está efectivamente resuelta.

El permiso de maternidad y el de lactancia tienen un recorrido histórico corto, que ha afectado decididamente en las condiciones laborales, así como de higiene y salud de las mujeres que han tenido hijos mientras han estado en activo. Es por este motivo que el planteamiento de estos permisos, como derecho inherente a toda madre, es relevante en la legislación social.

En este artículo se pretende focalizar la atención sobre uno de los períodos históricos en el que los derechos laborales de las mujeres retrocedieron en mayor medida: el franquismo. El Nuevo Estado expulsó a las mujeres casadas del mercado de trabajo ${ }^{4}$ y es por este motivo que nos preguntamos si las normas laborales sectoriales, esto es, las Reglamentaciones Nacionales de Trabajo, o más adelante, las Ordenanzas Laborales y

de 1 de marzo, de medidas urgentes para garantía de la igualdad de trato y de oportunidades entre mujeres y hombres en el empleo y la ocupación se publica en el BOE número 57, de 7 de marzo de 2019.

${ }^{3}$ Según el IDESCAT (Institut d'Estadística de Catalunya), en el año 2011 (el último sobre el que se obtuvieron datos), los hombres dedicaban una media diaria de 2:35 horas a "hogar y familia", mientras las mujeres dedicaban 4.14 horas, aproximadamente el doble de tiempo. En lo referente al Estado español, los datos del INE (Instituto Nacional de Estadística), nos indican que en 2016 las mujeres dedicaban 38 horas semanales al "cuidado o educación de los hijos", mientras los hombres dedicaban una media de 23 horas. En relación a la tarea "cocinar o hacer tareas domésticas", la dedicación de las mujeres ascendía a las 20 horas semanales, mientras entre los hombres era de 11 horas a la semana. Solamente es necesario consultar los datos estadísticos para comprobar que el tiempo de vida dedicado a las tareas de cuidados aún es mucho mayor, de media, entre las mujeres. Fuentes: http://www.idescat.cat y http://www.ine.es

${ }^{4}$ Aunque dicha circunstancia no significa que no desempeñaran una actividad laboral en la economía sumergida, como se ha analizado en diferentes estudios. 
Convenios Colectivos Sectoriales, recogían el permiso de lactancia para las mujeres trabajadoras que tenían hijos.

La intención inicial en el planteamiento sobre la metodología a seguir para realizar el análisis anunciado, además de buscar la literatura previa existente sobre la materia en relación al recorrido histórico del permiso de lactancia, ha sido buscar en qué sectores de producción existía una mayor ocupación de mujeres durante el franquismo, para ver cómo se regulaba esta cuestión en sectores altamente feminizados. Se buscó en los anuarios publicados en la página web del INE (www.ine.es), concretamente en los de 1943 (el primer año disponible finalizada la Guerra Civil), el de 1962 (el año posterior a la aprobación de la ley que permitiría, con reservas, a las mujeres casadas seguir en activo, como analizaremos más adelante) y el de 1975, coincidiendo con la muerte de Franco y para cerrar el ciclo. Cabe señalar que la búsqueda ha sido infructuosa por diferentes razones: falta de coincidencia en la calificación de los sectores y su numeración en los diferentes anuarios y, sobre todo, la falta de segregación de los datos de ocupación laboral por sexos. Así las cosas, no ha sido posible obtener datos objetivos sobre en qué sectores trabajaban más mujeres.

Es por este motivo que se ha optado por buscar la legislación sectorial laboral de aquellos sectores que, por conocimiento previo de la historia laboral de las mujeres, se intuye que se ocupó a un número importante de mujeres, también en el franquismo. Estos sectores son: comercio, enseñanza privada, industria química, industria vidrio, textil sector algodón y trabajo a domicilio en elaboración de vestidos. También, y por su importancia, se han incluido las Reglamentaciones Nacionales de Trabajo de una empresa de gran tamaño como fue la Telefónica Nacional de España, que contó con un gran número de mujeres entre sus empleados ${ }^{5}$.

En cada sector de producción, así como en el caso de las empresas, se aprobaron por lo menos dos normas reguladoras (aunque no en todos los casos) que corresponden en gran medida a la década de los años 40 y a las décadas de los años 60 o 70. Cabe señalar que en ese período de tiempo fueron muchas las cuestiones que cambiaron: la política del régimen sobe las mujeres y la legislación laboral que les era aplicable y los cambios económicos a partir del Plan de Estabilización Económica de 1959. Así, se estima que los cambios que devinieron al largo del franquismo repercutieron, de alguna manera, en la legislación laboral.

Los planteamientos formulados en relación al permiso de lactancia son los siguientes: ¿Se contemplaba en la legislación laboral y en las Reglamentaciones Nacionales de

\footnotetext{
${ }^{5}$ BorderíAs, C., Entre líneas. Trabajo e identidad femenina en la España Contemporánea. La Compañía Telefónica 1924-1980, Icaria Editorial, Barcelona, 1993.
} 
Trabajo y normas análogas? Y de ser así, ¿En qué términos? ¿Influyó de alguna manera la ley de 1961 en la regulación del permiso de lactancia? En este artículo intentaremos contestar estas preguntas analizando una muestra de dichas normas, considerando que el análisis de todas y cada una de las normas sectoriales y de empresa es una tarea que se escapa para un artículo académico de las características del presente. Quién sabe si una tarea de análisis más completa podría dar lugar a un trabajo más amplio.

\section{Antecedentes legales del permiso de lactancia}

Antes de entrar a analizar la legislación del período histórico estudiado, cabe hacer un breve repaso de los orígenes del permiso de lactancia. La primera norma en la que encontramos una referencia al puerperio y la lactancia es en la Ley dictando disposiciones para que los menores de ambos sexos que no hayan cumplido diez años no sean admitidos en ninguna clase de trabajos, sancionada el 13 de marzo de $1900 .^{6}$ Ésta norma regulaba la creación de las Juntas Provinciales de Reformas Sociales y las Juntas Locales de Reformas Sociales, y le otorgaba a la autoridad competente la misión de velar por la observancia de la moralidad y las buenas costumbres en aquellos centros de trabajo en los que se encontraran obreros de ambos sexos ${ }^{7}$. El artículo 9 de la norma regulaba las cuestiones referidas al alumbramiento y lactancia. En cuanto a ésta última cuestión, establecía lo siguiente:

"Las mujeres que tengan hijos, en el período de la lactancia, tendrán una hora al día, dentro de las del trabajo, para dar el pecho a sus hijos. Esta hora se dividirá en dos períodos de treinta minutos, aprovechables, uno, en el trabajo de la mañana, y otro, en el de la tarde. Estas medias horas serán aprovechadas por las madres, cuando lo juzguen conveniente, sin más trámite que participar al director de los trabajos, y al entrar en ellos, la hora que hubieren escogido. No será en manera alguna descontable, para el efecto de cobro de jornales, la hora destinada a la lactancia."

Este párrafo es el primero en toda la historia del Derecho Social en el que se reconoce este derecho, estableciendo un tiempo diario y sin que éste sea a cuenta de la trabajadora. Es decir, que el tiempo de lactancia disfrutado en horario laboral no se le restaba del sueldo a percibir. Un avance si tenemos en cuenta que el tiempo de puerperio sí era descontable.

\footnotetext{
${ }^{6}$ Gaceta de Madrid número 73, de 14 de marzo de 1900.

${ }^{7}$ ESPUNY, N., “Antecedentes históricos al permiso de lactancia.”, IUSLabor, no 2, 2006.
} 
En 1930 se aprueba un subsidio para las trabajadoras que lacten a su hijo, a raíz del Convenio adoptado por la Conferencia General de la Organización Internacional del Trabajo el 29 de octubre de 1919, que dio lugar al Seguro Médico de Maternidad, regulado por Real Decreto de 22 de marzo de $1929^{8}$ y su Reglamento, de 29 de enero de $1930^{9}$. En su Capítulo III, sobre Beneficios, establece que la mujer inscrita en el seguro tendrá derecho a percibir un subsidio cuando lacte a su hijo, además de regular otras medidas relacionadas con la salud de las madres y sus bebés lactantes, hasta el consejo de visitadoras entorno a la higiene y a la lactancia: solían ser las mismas matronas que promovían la permanencia de la lactancia materna ${ }^{10}$.

En la Segunda República (1931-1939), la protección de la maternidad se hizo presente en la legislación laboral. La Ley de Contrato de Trabajo de $1931^{11}$ en su artículo 90.3 prohibía el despido de trabajadoras por alumbramiento:

"Artículo 90. (...) Tampoco podrá darse por terminado el contrato de trabajo:

3. Por ausencia de la obrera fundada en el descanso que, con motivo del alumbramiento, señale la legislación vigente."

Siguiendo la política de protección de la mujer obrera que deviene madre, el 26 de mayo de 1931 se aprueba el Seguro de Maternidad ${ }^{12}$. En el preámbulo de esta norma se menciona la Conferencia Internacional del Trabajo celebrada en Washington en 1919, dónde se adquirió el compromiso internacional de cuidar a la mujer obrera que queda encinta y da a luz un hijo tanto antes como después del parto, así como hace referencia a la ley de 1900, la primera legislación laboral dirigida a proteger a la mujer en caso de alumbramiento. En el mismo texto, hace referencia al antecedente del Seguro de Maternidad de 1930. En éste seguro, que entró en vigor el 1 de octubre de 1931, se pretendía proteger, también, a las mujeres obreras no inscritas por culpa del patrono, siempre que lo hubieran denunciado con anterioridad ante la entidad aseguradora o la Instrucción y el patrono pagaran la cuota, y se ordenaba a los Ministerios de Gobernación e Instrucción pública la vigilancia del cumplimiento de la colaboración de los organismos y servicios de jurisdicción según el Decreto-ley de 22 de Marzo de 1929, con el objetivo de "dar la mayor y más fácil eficacia la misión sanitaria y

\footnotetext{
${ }^{8}$ Gaceta de Madrid número 83, de 24 de marzo de 1929.

${ }^{9}$ Gaceta de Madrid número 32, de 1 de febrero de 1930.

${ }^{10}$ EsPUNY, N., “Antecedentes históricos al permiso de lactancia.”, IUSLabor, nº 2, 2006.

${ }^{11}$ Gaceta de Madrid número 326, de 22 de noviembre de 1931.

${ }^{12}$ Gaceta de Madrid número 147, de 27 de mayo de 1931.
} 
protectora a la madre y del niño procurada por el Seguro de Maternidad"13. Así las cosas, la protección de la lactancia materna también quedaba protegida.

\section{Legislación laboral franquista: de la expulsión de las mujeres del mercado de trabajo a un retorno con reservas}

La implementación del Nuevo Estado finalizada la Guerra Civil española (1936-1939), supuso un cambio radical en la política de género respecto a los avances que se habían conseguido durante el período republicano. En el ámbito laboral, la Declaración II.1 del Fuero del Trabajo de $1938^{14}$ rezaba lo siguiente: "[e]n especial prohibirá el trabajo nocturno de las mujeres y niños, regulará el trabajo a domicilio y liberará a la mujer casada del taller y de la fábrica." De esta manera, salvo en las excepciones estipuladas en la Orden de 27 de diciembre de 1938, trabajo de la mujer, obreras en paro ${ }^{15}$, las mujeres casadas no podían realizar actividad laboral alguna y asé se regularía en las Reglamentaciones Nacionales de Trabajo ${ }^{16}$. Es de esta manera como, en principio y según la moralidad que se impone de manera más severa durante la dictadura franquista, las mujeres solteras que realizan una actividad laboral no devienen madres mientras están en activo (otra cosa era si, en realidad, algunas mujeres tenían hijos sin haber contraído matrimonio). ¿Era necesario, entonces, que bajo esta premisa la legislación laboral protegiera la maternidad y la lactancia? El Libro I de la Ley de Contrato de Trabajo de 1944, aprobado por Decreto de 26 de enero de 1944, ${ }^{17}$ establece en su artículo $11 \mathrm{~d}$ ) que podrá concretar la prestación de sus servicios: "[1] a mujer casada, con autorización de su marido, salvo el caso de separación de derecho o de hecho, en el que se reputará por concedida por ministerio de la Ley para todos los efectos derivados del contrato, incluso el percibo de la remuneración." Según el dictado de la ley, era posible que algunas mujeres obreras fueran madres durante su vida laboral, aunque en esa etapa del franquismo no fuera probable. Aunque no existan datos estadísticos al respecto, por anteriores investigaciones de la autora se pone en duda que en esa etapa del franquismo hubiera muchas mujeres casadas que siguieran en el mercado laboral después de contraer matrimonio. Otra cosa era que esas mujeres trabajaran en la economía sumergida o en casa. Aunque esa era la situación generalizada, el Libro II de la Ley de Contrato de Trabajo de 1944, aprobado por

\footnotetext{
${ }^{13}$ CABEZA, S., "Legislación protectora de la maternidad en la Restauración española", Cuadernos de Historia Moderna y Contemporánea, VI, 1985, p. 147-162.

${ }^{14}$ BOE número 505, de 10 de marzo de 1938.

${ }^{15}$ BOE número 183, de 31 de diciembre de 1938.

${ }^{16}$ EsPUNY, M. J., “Aproximación histórica al principio de igualdad de género (II): el femenino después de la guerra.”, IUSLabor, n 1, 2007 y ESPUNY, M. J., “Aproximación histórica al principio de igualdad de género (y III): las Reglamentaciones de Trabajo, observatorios de desigualdad”, IUSLabor, nº 2, 2007.

${ }^{17}$ BOE número 55, de 24 de febrero de 1944.
} 
Decreto de 31 de marzo de 1944, por el que se aprueban los textos refundidos de las Leyes de Contrato de embarque, aprendizaje y trabajo de mujeres y niños y trabajo a domicilio, ${ }^{18}$ en sus artículos 166, 167 y 168 regula la protección a la maternidad y la lactancia. Sobre la lactancia, la letra de la norma tenía una redacción muy parecida a la de la Ley de 13 de marzo de $1900^{19}$ :

"Aún cuando no conste en el contrato, las mujeres, mientras tengan hijos en período de lactancia, tendrán derecho, siempre dentro de la jornada de trabajo, a una hora de descanso al día, divisible en dos períodos de media hora cada uno.

Estos descansos serán utilizados por las madres cuando lo juzguen conveniente, sin más que comunicar al director o representante de la empresa, al entrar al trabajo, la hora que hubieren escogido. No será en manera alguna descontable de los jornales el tiempo destinado a la lactancia".

La situación laboral de las mujeres volvió a ser objeto de regulación en la Ley 56/1961, de 22 de julio de 1961, sobre derechos políticos, profesionales y de trabajo de la mujer. ${ }^{20}$ En esta reforma, la excedencia por razón de matrimonio del personal femenino regulada en las Reglamentaciones Nacionales de Trabajo sectoriales y empresariales, institución jurídica existente a tenor de la letra del Fuero del Trabajo de 1938 citada anteriormente, pasa de ser forzosa a voluntaria. En su artículo cuarto establecía lo siguiente:

"En las reglamentaciones de trabajo, convenios colectivos y reglamentos de empresa, no se hará discriminación alguna en perjuicio del sexo o del estado civil, aunque éste último se altere en el curso de la relación laboral."

Éste extremo se concreta en el Decreto 258/1962, de 1 de febrero, por el que se aplica a la esfera laboral la Ley 56/1961, de 22 de julio, que equipara a los trabajadores de uno y otro sexo en sus derechos de orden laboral. ${ }^{21}$ Ésta norma establecía que el cambio de estado civil no rompía la relación laboral, aunque, siguiendo la moral imperante durante la dictadura franquista, no se podía perder de vista "la defensa del hogar familiar". Así, las mujeres que contraían matrimonio podían elegir entre las opciones que se anunciaban en el artículo segundo de la norma ${ }^{22}$ :

\footnotetext{
${ }^{18}$ BOE número 102, de 11 de abril de 1944.

${ }^{19}$ ESPUNY, N., “Antecedentes históricos al permiso de lactancia.", IUSLabor, nº 2, 2006.

${ }^{20}$ BOE número 173 , de 24 de julio de 1961.

${ }^{21}$ BOE número 41, de de 16 de febrero de 1962.

${ }^{22}$ ESPUNY, M. J., "Aproximación histórica al principio de igualdad de género (II): el femenino después de la guerra.", IUSLabor, no 1, 2007.
} 
"Primera. Continuar su trabajo en la empresa.

Segunda. Rescindir su contrato con percibo de la indemnización que se señalen las disposiciones estatales susceptibles de ser mejoradas en convenios colectivos sindicales y Reglamentos de régimen interior de las empresas respectivas.

Tercera. Quedar en situación de excedencia voluntaria por un perlado no Inferior a un año ni superior a cinco."

Según la doctrina de la época, dicha reforma se llevó a cabo porque "La mujer casada tiene un derecho pleno y riguroso a seguir al servicio de la Empresa que contrató sus servicios como soltera"23. Ésta norma devuelve a la mujer el derecho a tomar la decisión sobre su futuro laboral, aunque la realidad no fuera exactamente así y existieran presiones familiares y sociales para que las mujeres ejercieran su papel de ángel del hogar y se quedaran en casa haciéndose cargo de las tareas de cuidados de hijos y mayores dependientes ${ }^{24}$. El cambio legal implicaba, en principio, una mayor permanencia en las empresas de mujeres que contraían matrimonio, o, en su caso, la incorporación de mujeres casadas. En ambos casos, esas mujeres eran susceptibles de ser madres durante su trayectoria laboral.

\section{Análisis de Reglamentaciones Nacionales de Trabajo, Ordenanzas de Trabajo y los Convenios Colectivos Sindicales sectoriales y de empresa}

Las normas reguladoras de las condiciones laborales de los trabajadores y trabajadoras tomaron diferentes denominaciones en el transcurso del franquismo, aunque el espíritu de dichas normas fuera el mismo: establecer las normas de mínimos que debían regir las relaciones laborales entre empresarios y trabajadores.

Las Reglamentaciones Nacionales de Trabajo establecían las condiciones generales de las relaciones laborales entre patronos y trabajadores en el seno de la empresa, a dispensas de lo establecido en la Declaración III.4 del Fuero del Trabajo de $1938 .^{25} \mathrm{La}$ competencia en la materia recaía sobre el Ministerio de Trabajo, sin ser posible delegación alguna sobre la misma, motivo por el cuál era el Estado el que regulaba las relaciones laborales de forma privativa y en "régimen de monopolio" "26. Es la Ley de 16 de octubre de 1942 por la que establecen normas para elaborar Reglamentaciones

\footnotetext{
${ }^{23}$ Alonso, M., "La Ley de 24 de julio de 1961 sobre Derechos políticos, profesionales y de trabajo de la mujer", Revista de Administración Pública, no 36, 1961, p. 327-354.

${ }^{24}$ VELO, E., "Trabajo femenino y comercio familiar. El Poble Sec en la Barcelona en la posguerra", IUSLabor, $\mathrm{n}^{\mathrm{o}}$ 3, 2018.

${ }^{25}$ BOE número 505, de 10 de marzo de 1938.

26 EsPUNY, M. J., “Aproximación histórica al principio de igualdad de género (y III): las Reglamentaciones de Trabajo, observatorios de desigualdad”, IUSLabor, no 2, 2007.
} 
Nacionales de Trabajo $^{27}$ dónde se enumeran los principios y elementos básicos que deben contener estas normas, dirigidos a regular las relaciones entre empresario y trabajador en cada rama de producción o empresa, según su ámbito de aplicación. En cuanto a la aplicación territorial, aunque se reconocía la posibilidad que se aprobaran en un ámbito regional o provincial, entre otras divisiones territoriales, el artículo segundo señalaba la preferencia de reglamentaciones nacionales, para evitar que normas de rango territorial más restringido "regulasen las condiciones laborales de una misma rama de la producción".

La Ley de 24 de abril de 1958 sobre convenios colectivos sindicales, ${ }^{28}$ en aras de la oportunidad que implica, según su preámbulo, la renovación industrial que se vivía en esos tiempos debía incidir en la mejora de las condiciones de trabajo. Además, delega en la Organización Sindical, con la colaboración de empresarios y trabajadores, la tramitación de los convenios sindicales, aunque el Ministerio de Trabajo, fuera en la Delegación Provincial de Trabajo o Dirección General se reservaba la competencia de aprobar el convenio propuesto. En el mismo sentido que las Reglamentaciones, estos convenios contenían las condiciones mínimas de trabajo en sus diferentes aspectos: salarios, categorías profesionales y jornadas y horarios de trabajo, entre otros.

Finalmente, y en tiempo posterior a la Ley 56/1961 que implicaba algunos cambios para las mujeres en el ámbito laboral, se aprueba la Ley 18/1973, de 19 de diciembre, de Convenios Colectivos Sindicales de Trabajo. ${ }^{29}$ El objetivo de esta Ley es que los Convenios Colectivos Sindicales que se aprueben mejoren las condiciones de los trabajadores, contenidas en las Reglamentaciones y Ordenanzas Laborales. Otorga a las representaciones sindicales la iniciativa para revisar o establecer un Convenio Colectivo, que deberá autorizar la Organización Sindical. Las negociaciones para la articulación del Convenio se llevarán a cabo bajo supervisión de la Organización Sindical y deberá estar presentes una representación de los empresarios y de los técnicos y trabajadores, a partes iguales. A pesar de los cambios pretendidos y la pretendida apertura para que los actores implicados en las condiciones de trabajo en el seno de la empresa participaran de la negociación en la elaboración de estas normas, la última palabra sobre las mismas la tenían la Organización Sindical y el Ministerio de Trabajo. Así mismo, nos podemos preguntar si en las negociaciones que se anuncian en la Ley de 1973 en alguna ocasión acudía alguna mujer en representación de las trabajadores y trabajadoras, puesto que el único estamento de carácter organizativo que puede participar en esas cuestiones es la Organización Sindical y, debido a las costumbres y

\footnotetext{
${ }^{27}$ BOE número 296, de 23 de octubre de 1924

${ }^{28}$ BOE número 99, de 25 de abril de 1958.

${ }^{29}$ BOE número 3, de 3 de enero de 1974.
} 
las dificultades que tenían las mujeres trabajadores en esa materia, cabe la duda razonable que alguna mujer participara de la elaboración de esas normas y, en consecuencia, vertiera su experiencia sobre las necesidades de las trabajadoras en ámbitos como la higiene y salud laboral, riesgos laborales durante el embarazo y necesidades entorno a la lactancia materna, el tema que nos ocupa. Se trataría, entonces, de una legislación laboral elaborada por hombres que regula, también, las necesidades de las mujeres sin que éstas, presuntamente, estén presentes en su negociación y configuración.

A continuación, se analizará de forma sistemática la inclusión del permiso de lactancia en normas sectoriales de diferentes ramas de producción y tres de empresa. En cuanto a las ramas de producción, se han elegido conforme a una variedad de sectores, que comprenden desde la atención al cliente, así como la industria y el trabajo a domicilio. El análisis ha recaído en las siguientes ramas de producción y sus respectivas normas:

a) Comercio al detalle:

- Orden de 10 de febrero de 1948 por el que se aprueba la Reglamentación Nacional de Trabajo en el comercio. ${ }^{30}$

- Orden de 24 de julio de 1971 por la que se aprueba la Ordenanza de Trabajo para el Comercio. 31

b) Enseñanza privada:

- Orden de 20 de septiembre de 1943 por la que se aprueba la Reglamentación de Trabajo de la Enseñanza Privada. ${ }^{32}$

- Orden de 30 de septiembre de 1970 por la que se aprueba la Ordenanza Laboral para la enseñanza no estatal.33

- Orden de 25 de septiembre de 1974 por la que se aprueba la Ordenanza Laboral para los centros de enseñanza. ${ }^{34}$

c) Industrias del vidrio:

- Orden de 21 de septiembre de 1946 por la que se aprueba la Reglamentación Nacional de Trabajo para las Industrias del Vidrio. ${ }^{35}$

- Orden de 28 de agosto de 1970, por la que se aprueba la Ordenanza de Trabajo de la Construcción, Vidrio y Cerámica.36

\footnotetext{
${ }^{30}$ BOE números 97 a 103, de 6 a 12 de abril de 1948.

${ }^{31}$ BOE número 194, de 14 de agosto de 1971.

${ }^{32}$ BOE número 266, de 23 de septiembre de 1943.

${ }^{33}$ BOE número 251, de 20 de octubre de 1970.

${ }^{34}$ BOE número 232, de 27 de septiembre de 1974.

${ }^{35}$ BOE número 272, de 29 de septiembre de 1946.

${ }^{36}$ BOE número 213 a 216, de 5 a 9 de septiembre de 1970.
} 
d) Industria textil sector algodón e industria del vestido y tocado, que confluyen en una misma norma reguladora:

- Orden de 1 de abril de 1943, por la que se aprueba la Reglamentación Nacional de Trabajo en el Sector Algodón de la Industria Textil. ${ }^{37}$

- Orden de 16 de julio de 1948 por la que se aprueba la Reglamentación Nacional de Trabajo en las Actividades de Confección, Vestido y Tocado. ${ }^{38}$

- Orden de 21 de septiembre de 1968 por la que se aprueba la Ordenanza Laboral para la Industria Textil. ${ }^{39}$

e) Compañía Telefónica Nacional de España:

- Orden de 20 de junio de 1947 por la que se aprueba la Reglamentación Nacional de Trabajo de la Compañía Telefónica Nacional de España. ${ }^{40}$

- Orden de 10 de noviembre de 1958 por la que que se aprueba el nuevo texto refundido de la Reglamentación Nacional de Trabajo de la Compañía Telefónica Nacional de España. ${ }^{41}$

f) Galerías Preciados, S.A. (empresa que guarda relación con el sector del comercio al detalle):

- Orden de 31 de octubre de 1959 por la que se aprueba la Reglamentación Nacional de Empresa "Galerías Preciados, S.A."42

g) Tabacalera, S.A.:

- Orden de 28 de junio de 1946 por la que se aprueba la Reglamentación Nacional del Trabajo en la Compañía “Tabacalera, S.A.”.43

En las ramas de producción analizadas el personal femenino estaba muy presente, así como en la Compañía Telefónica Nacional de España, en Galerías Preciados y la Tabacalera, en la tarea de fabricación de cigarros, esto es, las conocidas como "cigarreras" 4 . En ninguna de las normas analizadas se regula de forma específica el derecho de las mujeres con hijos lactantes a dedicar un tiempo de la jornada laboral a dar el pecho, aunque no podemos descartar que se incluyera en los reglamentos de régimen interior de las empresas, previstos en las mismas normas sectoriales. En cualquier caso, estas disposiciones no son objeto del presente estudio. En cualquier caso, la falta de regulación específica del permiso de lactancia nos llevaría a aplicar lo

\footnotetext{
${ }^{37}$ BOE número 121 , de 1 de mayo de 1943.

${ }^{38}$ BOE número 183, de 1 de julio de 1948.

${ }^{39}$ BOE número 231, de 27 de septiembre de 1965.

${ }^{40}$ BOE número 191, de 10 de julio de 1947.

${ }^{41}$ BOE número 283, de 26 de noviembre de 1958.

${ }^{42}$ BOE número 302, de 18 de diciembre de 1959.

${ }^{43}$ BOE número 185, de 4 de julio de 1946.

${ }^{44}$ GÁlveZ, L., Compañía Arrendataria de Tabacos, 1887-1945. Cambio tecnológico y empleo femenino, LID Editorial Empresarial, Madrid, 2000.
} 
dispuesto en el artículo 168 de la Ley de Contrato de Trabajo de 1944 según lo anunciado en el artículo 12 de la ley de reglamentaciones nacionales de trabajo de 1942 disponía, y así se ha seguido aplicando en la legislación social, que las materias no reguladas expresamente en las reglamentaciones de trabajo se entendería que eran de aplicación de manera irrenunciable las disposiciones legales en materia social de carácter general. Así, aunque en las normas analizadas no se regulara de manera específica, las trabajadoras tenían derecho a disfrutar del permiso de lactancia según lo establecido en la ley de contrato de trabajo de 1944, a pesar de que su aplicación no sea efectivamente demostrable únicamente por su anunciado en la ley.

En lo que al personal femenino se refiere, además de la ausencia de una regulación que adaptara el permiso de lactancia a los puestos de trabajo ocupados por las mujeres en las respectivas ramas de producción o empresa, o tan siquiera repitiera lo establecido en la legislación social general, en las normas estudiadas se han identificado algunas peculiaridades que se estima pertinente enumerar por ser cuestiones relacionadas con las mujeres trabajadoras y que son un ejemplo del trato recibido en la legislación laboral franquista. Como ejemplo, en las normas reguladoras de la enseñanza privada y en la Reglamentación Nacional de Trabajo de "Tabacalera, S.A.", en la regulación de los supuestos que dan lugar a una excedencia forzosa, no se contempla el supuesto de matrimonio del personal femenino, ni en la norma de 1943 ni la de 1949, período muy restrictivo en cuanto a la ocupación laboral de las mujeres casadas. La falta de previsión de la excedencia por ese motivo se puede dar por la alta feminización ambos sectores ${ }^{45}$. Lo que sí se regula en las ordenanzas laborales de enseñanza privada de 1970 y 1974, en sus artículos 37 y 40 respectivamente, es la previsión de una cuestión íntimamente vinculada con la maternidad de las empleadas: la de licencia para la mujer gestante desde dos meses antes de la fecha prevista para el parto y hasta cuarenta y cinco días después que éste haya tenido lugar. En ésta última norma también se indicaba que la licencia sería retribuida: "[e]sta licencia retribuida será a razón del salarlo real que corresponda a la categoría profesional de la trabajadora. Se deducirán por la Empresa las cantidades que la Seguridad Social abone por dicha causa."

En la industria del vidrio, una rama de trabajo altamente feminizado fue la de fabricación de ortopedia, lo que normalmente se denomina como lentes de contacto ${ }^{46}$. En la norma de 1970, su artículo 54 se dedica al personal femenino, indicando que "la Ordenanza seguiría el principio de igualdad entre ambos sexos, evitándose cualquier

\footnotetext{
${ }^{45}$ GÁlvez, L., Compañía Arrendataria de Tabacos, 1887-1945. Cambio tecnológico y empleo femenino, LID Editorial Empresarial, Madrid, 2000 y ARAQUE, N., "La formación de las maestras durante la primera etapa del franquismo", Tendencias Pedagógicas, n 14, 2009, p. 117-127.

${ }^{46}$ Velo, E., Dones i treball al Poble Sec durant el franquisme, Edicions de 1979, Barcelona, 2017.
} 
discriminación en perjuicio de la mujer en materia de aprendizaje, admisión, períodos de prueba, clasificación, ascensos, retribuciones, por trabajos especiales (...)" estableciendo, además, que las mujeres disfrutarían de los mismos sueldos y jornales que sus compañeros varones que desempeñaran trabajos y funciones iguales. A pesar de esa igualdad de trato anunciada, cabe señalar que la misma norma, en su artículo 134 regulaba la excedencia voluntaria del personal femenino por razón de matrimonio, lo que no contemplaba para el personal masculino, como tampoco se contemplaba en ninguna otra norma por ser una discriminación exclusivamente hacia las mujeres.

En cuanto al sector textil, encontramos algunas especificaciones como el cobro del plus familiar. En el apartado noveno de la Disposición adicional primera de la norma de 1943 se establece que, en el caso que ambos cónyuges trabajaran en misma o diferente empresa, en la misma o diferente actividad, el plus familiar sería percibido por el esposo, con excepción si en la rama de producción en la que trabajara no se contemplara este beneficio social. En cuanto a la excedencia por razón de matrimonio, en la reglamentación de vestido y tocado de 1948 no se contempla la excedencia del personal femenino que contrajera matrimonio y en la de la industria textil de 1965 ya se especificaba el carácter voluntario de tal excedencia, pocos años después de la ley de 1961 que cambia el sentido de tal obligación para las mujeres. Además, en su artículo 104 se establece que la retribución salarial del personal femenino no será diferente a la del personal masculino que realice trabajos de igual valor, entendiéndose así el de "igual clasificación profesional y la de puesto de trabajo, así como la función, actividad, rendimiento y tarea."

Por último, en las normas reguladoras de las relaciones de trabajo en la Compañía Telefónica Nacional de España, a pesar del gran número de mujeres que trabajaban como telefonistas en la empresa, tampoco encontramos una regulación específica del permiso de lactancia. Relacionado en cuestiones que también afectaban a las trabajadoras y como curiosidad, en el artículo 123 de su Reglamentación se regulaba la excedencia forzosa del personal, que en los hombres se indicaba a los setenta años y en las mujeres a los sesenta y cinco, como si las capacidades laborales del personal femenino mermaran antes que las de los hombres.

\section{Conclusiones}

La legislación social franquista es un claro ejemplo del lugar que se reservaba a las mujeres en el mundo del trabajo en ese período histórico, en especial a las casadas y, en este caso, a las que devenían madres. 
En las reglamentaciones nacionales de trabajo, ordenanzas laborales y convenios colectivos sindicales analizados no encontramos una regulación específica del permiso de lactancia que se adaptara a las características y necesidades de las trabajadoras de las empresas de las ramas de producción, o a las empresas objeto de regulación, según el puesto de trabajo que ocuparan y sus peculiaridades. De esta manera, las mujeres trabajadoras con hijos lactantes disponían de un derecho regulado en una norma generalista, la Ley de Contrato de Trabajo de 1944, que anunciaba la articulación de un derecho tal y como se había configurado en la Ley de 13 de marzo de 1900 de mujeres y niños, sin actualizarlo en más de 40 años. En cualquier caso, cabe indicar que la ley de 1944 prevé la aplicación de este derecho, aunque no conste en el contrato de trabajo de la mujer, extremo que se puede interpretar como una voluntad de proteger el derecho de la madre a lactar a su hijo e, igualmente, el derecho del hijo a ser alimentado con leche materna, medida higienista dirigida a mejorar la salud de los recién nacidos. A pesar de ello, se estima que un derecho tan importante tanto para las madres como para los hijos, que ya se reconoció en la primera legislación social, debería constar en las normas sectoriales y de empresa para reconocerse de una manera más firme y más fácilmente conocedora para las mujeres trabajadoras, así como para poder adaptarse a las características propias de los puestos de trabajo ocupados por mujeres en cada rama de producción o empresa. La no inclusión de ese derecho hace posible que su cumplimiento no fuera una cuestión prioritaria para los empresarios.

En el análisis de una cuestión como la lactancia materna es pertinente señalar que hasta la década de los 60 muchas mujeres que contraían matrimonio abandonaban su puesto de trabajo con el objetivo, precisamente, cuidar a la familia tal y como lo anunciaban normas como el Fuero del Trabajo de 1938 y el Fuero de los Españoles de 1945. Así, si las mujeres trabajadoras devenían madres una vez casadas y fuera de la empresa ¿era necesario contemplar el permiso de lactancia? Considerando que la misma normativa social abría una posibilidad que las mujeres casadas pudieran trabajar con el permiso del marido y que la orden que regulaba la inscripción de las mujeres en paro de 1938 también anunciaba la posibilidad que las mujeres casadas pudieran trabajar si devenían cabezas de familia o por otras circunstancias que imposibilitaban el trabajo del cónyuge, es posible que muchas de ellas fueran madres con hijos lactantes a cargo. Además, también se debe tener en cuenta que, a pesar de la moral de la época, era posible que mujeres trabajadoras solteras también fueran madres, en algunos casos debido a abusos sexuales y la imposibilidad de poder abortar de forma segura para la vida de la mujer si ese era su deseo, por ser un derecho totalmente prohibido durante el franquismo.

Como se ha podido comprobar en las normas analizadas, es relevante como la ausencia de un derecho tan importante como el permiso de lactancia se contrasta con la regulación minuciosa de aquellas cuestiones que suponen una discriminación para las 
mujeres. Las reglamentaciones nacionales de trabajo eran, como ya anunciaba la Dra. Maria Jesús Espuny en su artículo de 2007 publicado en IUSLabor, observatorios de desigualdad. De esta manera, en la mayoría de reglamentaciones sectoriales sí se regula la excedencia forzosa por razón de matrimonio del personal femenino, con algunas excepciones comentadas anteriormente. En este sentido, las normas aprobadas después de la ley de 1961 también hacen hincapié en el cambio de esa excedencia de forzosa a voluntaria. Otras cuestiones que implican discriminaciones para las mujeres es la regulación de diferencias salariales entre mujeres y hombres hasta la década de los 60 y 70, la preferencia del cobro del plus familiar por parte del cónyuge varón y la obligatoriedad de la jubilación de las mujeres cinco años antes que los hombres, como se establecía en las normas de la Compañía Telefónica Nacional de España, como si las mujeres en su totalidad perdieran las competencias para trabajar antes que los hombres. A pesar de ser unas normas altamente discriminatorias para las mujeres, es justo indicar que, fuera por inspiración de la legislación social de la restauración, por las características del trabajo o por la alta feminización del sector, en las normas de enseñanza privada sí se establece el derecho de las trabajadoras gestantes de acogerse a una licencia retribuida desde dos meses antes de la fecha prevista de parto y hasta cuarenta y cinco días después. Esta regulación deviene una excepción en la normativa analizada que sí implica una mejora en la calidad de vida de las mujeres trabajadoras gestantes, así como un mayor cuidado del hijo.

Por último, considerando la normativa analizada, regular el permiso de lactancia no era una prioridad para el régimen más allá de contemplarlo en la Ley de Contrato de Trabajo de 1944, pues el lugar para las mujeres era, según su ideario, el hogar. En este sentido, ni tan siquiera la aprobación de la ley de 1961 que permite a las mujeres poder elegir permanecer en la empresa después de haber contraído matrimonio, significa un cambio en la regulación del permiso de lactancia. Como se ha podido comprobar, las normas sectoriales y de empresa aprobadas después de esa fecha tampoco contienen una regulación específica del permiso de lactancia, motivo por el cual se presume que seguía siendo un derecho de segunda clase sin apenas importancia para el legislador social, esto es, en un primer momento el Ministerio de Trabajo con la colaboración, años más tarde, de la Organización Sindical y los empresarios. Como vemos, la no participación de mujeres en la elaboración de las normas implica que los derechos que pudieran mejorar su situación (y en este caso la de sus hijos) quedan en un segundo plano.

\section{Bibliografía}

Alonso, M., "La Ley de 24 de julio de 1961 sobre Derechos políticos, profesionales y de trabajo de la mujer", Revista de Administración Pública, nº 36, 1961, p. 327-354. 
ARAQUE, N., "La formación de las maestras durante la primera etapa del franquismo", Tendencias Pedagógicas, nº 14, 2009, p. 117-127.

BORDERÍAS, C., Entre líneas. Trabajo e identidad femenina en la España Contemporánea. La Compañía Telefónica 1924-1980, Icaria Editorial, Barcelona, 1993.

CaAmaño, E., "Lactancia", Baylos, A., Florencio, C., García, R., Casas, M. E. (Coords.), Diccionario internacional de Derecho del Trabajo y de la Seguridad Social, Tirant lo Blanch, Valencia, 2014, p. 1293-1298.

CABEZA, S., "Legislación protectora de la maternidad en la Restauración española", Cuadernos de Historia Moderna y Contemporánea, VI, 1985, p. 147-162.

ESPUNY, N., “Antecedentes históricos al permiso de lactancia.”, IUSLabor, n 2, 2006.

ESPUNY, M. J., “Aproximación histórica al principio de igualdad de género (II): el femenino después de la guerra.”, IUSLabor, nº 1, 2007.

ESPUNY, M. J., “Aproximación histórica al principio de igualdad de género (y III): las Reglamentaciones de Trabajo, observatorios de desigualdad”, IUSLabor, n 2, 2007.

EsPunY, M. J., “Aproximación histórica al principio de igualdad de sexos (IV): De la Ley de Contrato de Trabajo de 1944 a las últimas disposiciones franquistas.", IUSLabor, $\mathrm{n}^{\circ}$ 1, 2008.

EsPUNY, M. J., "El descanso puerperal y su cumplimiento”, FRANCO, G. (Directora), Debates sobre maternidad en una perspectiva histórica, Icaria Editorial, Barcelona, 2010, p. 189-205.

ESPUNY, M. J., "La primera legislación social protectora de la mujer: una perspectiva comparada.", RAmos, I. (Coordinadora), Derecho y trabajo en el siglo XIX, Dykinson, Madrid, 2017, p. 81-148.

GÁlvez, L., Compañía Arrendataria de Tabacos, 1887-1945. Cambio tecnológico y empleo femenino, LID Editorial Empresarial, Madrid, 2000.

GARCíA, G., "La protección a la maternidad: cien años de la Ley de 8 de enero de 1907”, IUSLabor, n 2, 2007. 
Llorens, B., Ferrer, M.E., Morales, V., Alenda, A., "Creíamos en la lactancia materna. Una aproximación en la experiencia de tres generaciones.", Índex de enfermería: información bibliográfica, investigación y humanidades, Año 16, no 58 , 2007, p. 34-38.

LOUSADA, J.F., "El permiso de lactancia”, Relaciones laborales: Revista crítica de teoría y práctica, no 2, 1996, p. 151-183.

NiElfa, G., “¿El siglo de las mujeres?”, Cuadernos de Historia Contemporánea, $\mathrm{n}^{\circ}$ 21, 1999, p. 63-81.

TORO, R., "Evolución histórica de la lactancia materna: derechos y conciliación familiar.", Revista ROL de enfermería, vol. 33, n 12, 2010, p. 48-54.

Velo, E., Dones i treball al Poble Sec durant el franquisme, Edicions de 1979, Barcelona, 2017.

Velo, E., "Trabajo femenino y comercio familiar. El Poble Sec en la Barcelona en la posguerra", IUSLabor, no 3, 2018. 